\title{
Chemical composition and antifungal activity of oill extracted from leaves turmeric (Curcuma longa)
}

\section{Rini Yanti ${ }^{1 *}$, Hermina Nurdiawati ${ }^{1}$, Puji Wulandari ${ }^{2}$, Yudi Pranoto ${ }^{1}$, Muhammad Nur Cahyanto $^{1}$}

${ }^{1}$ Department of Food and Agricultural Product Technology, Agricultural Technology Faculty, Gadjah Mada University, Indonesia

${ }^{2}$ Department of Food Technology, Agricultural Faculty, Sultan Ageng Tirtayasa University, Indonesia

\section{Abstract}

Turmeric rhizomes are commonly used in the culinary, pharmaceutical, herbal medicine, and beverage industries. On the contrary, turmeric leaves are underutilized. The aims of this study were to extract the essential oil from turmeric leaves, characterize the chemical composition of the oil, and determine its antifungal activities against aflatoxinproducing fungi. Steam distillation was used to extract the essential oil from turmeric leaves. The properties of the oil were identified using GCMS. Antimicrobial activities against Aspergillus flavus and Aspergillus parasiticus were determined. Spores of the fungi were inoculated into potato dextrose agar plates supplemented with various quantities of turmeric leaves essential oil and incubated at $30^{\circ} \mathrm{C}$ for 7 days. The oil's primary constituents were $\alpha$-phelandrene $(46.70 \%)$, followed by $\alpha$ terpinolene $(17.39 \%), 1,8$-cineole $(8.78 \%)$, benzene $(4.24 \%)$, and $2-\beta$ pinene $(3.64 \%)$. At low $(<1 \%)$ concentrations, the oil delayed mycelia formation and at high concentrations it significantly inhibit fungal growth (at $1 \%$ ) and completely inhibit colony formation (at $2 \%$ ). Additionally, the result show that turmeric leaves oil can inhibited fungus growth at the lowest concentration $(0.25 \%)$ when compared to the control over a seven-day incubation period.

\section{Article History}

Received July 05, 2021

Accepted Nov 11, 2021

Keyword

Turmeric leave,

Essential oil,

Antifungal,

Aspergillus flavus,

Aspergillus parasiticus

\section{Introduction}

Curcuma is the largest genus in the Zingiberaceae family and is frequently used in the manufacture of spices, pharmaceutical products, dyes, and decorative plants. There are approximately 93-100 Curcuma species known (1). Turmeric (Curcuma longa) is one of the species that indigenous to South Asia (India, East Indies, Sri Lanka, Pakistan, and Bangladesh), East Asia (China and Taiwan), Southeast Asia (Thailand, Burma, and Indonesia), as well as northern Australia (2). The rhizome of turmeric is widely used in Indonesia's culinary, medicinal, traditional herb, and beverage industries. Turmeric leaves, on the other hand, are underutilized and generate waste during post-harvest processing. Traditionally, the leaves were mostly applied as a flavouring agent in cooking, especially in the Minangkabau cuisine of West Sumatera. Moreover, recent findings show that turmeric leaves and stems have their own biological or chemical activities due to the curcumin and other medicinal components in the leaves and stem (3). Turmeric leaves contain oil approximately $0.53 \%$ (weight basis). Several studies (4) demonstrated that turmeric leaves 
oil was effective against Escherichia coli, an antibiotic-resistant bacteria, and oil from Curcuma longa leaves possessed antioxidant properties $(3,5)$.

Aspergillus flavus and Aspergillus parasiticus were discovered as contaminants in cereals and legumes, respectively $(6,7)$. Both fungi destroy the product's quality and produce mycotoxins. Aflatoxin is a mycotoxic substance generated by Aspergillus flavus and Aspergillus paraciticus. Aflatoxin B1 is the form of aflatoxin that is most harmful to animals and people health (8).

Aflatoxin is most likely to cause mutagenic, carcinogenic, teratogenic, hepatotoxic, and immunosuppressive effects, as well as to inhibit certain metabolic systems (6). The metabolic systems affected include nutritional disorders such as kwashiorkor and offbalance growth-which is most likely by interfering micronutrient absorption (e.g., zinc, iron, and vitamins), protein synthesis, and metabolic enzyme activities (9).

Aflatoxins have a relatively stable molecular structure. The decomposition temperatures range between 237 and $306^{\circ} \mathrm{C}$, and they are extremely resistant to dry heat (melting point $268-269^{\circ} \mathrm{C}$ ) (10). While heating at a higher temperature can reduce aflatoxin levels, it also reduces the nutritional value of the product. To avoid aflatoxin contamination in foods, it is necessary to suppress the growth of $A$. flavus and $A$. paraciticus.

The treatments traditionally used to control the growth of fungi are mostly synthetic fungicides. However, in the past few decades, studies on natural products to replace synthetic additives and preservatives in the food industry have grown tremendously. When used in relatively high concentrations, chemicals such as benzomidazole group and inhibitors of aromatic hydrocarbons biosynthesis have residual risks of being carcinogenic. Natural substances such as essential oils have emerged as a promising and effective compounds to protect food products from microbial contamination. Some essential oils have been classified as GRAS (Generally Recognized as Safe) and have shown antifungal and antibacterial activities against various microorganisms (11). Therefore, the objectives of this study were to extract the essential oil from turmeric leaves, characterize its chemical composition, and determine turmeric oil's antifungal activity against aflatoxin-producing fungi.

\section{Materials and Methods}

\subsection{Preparation of Essential Oil}

Turmeric leaves were collected from Yogyakarta's Beringharjo traditional market. The leaves were washed in running water and cut into pieces between 1-2 cm in length and dried in a cabinet dryer. Steam distillation was used to extract essential oils from the leaves. The distillation process lasted four hours; timed when the distillate began to drip. The distillate was in the form of oil-water mixture, which was later separated using a separator funnel. Anhydrous $\mathrm{Na}_{2} \mathrm{SO}_{4}$ (Merck, Germany) was added in a ratio of $1: 10(\mathrm{~g} / \mathrm{ml}$ ), and the mixture was filtered using Whatman 42 paper (GE Healthcare, UK). The essential oil obtained was stored in a tightly closed dark bottle and kept at a temperature of $4^{\circ} \mathrm{C}$ for further analysis (12). 


\subsection{Preparation of Aspergillus Spore}

Aspergillus flavus (FNCC 6133) and Aspergillus parasiticus (FNCC 6033) were obtained from Gadjah Mada University's Food and Nutrition Culture Collection. A. flavus and $A$. parasiticus microbial strains were seeded on slanted Potato Dextrose Agar (PDA) (Merck, Germany) and incubated at $30^{\circ} \mathrm{C}$ for 7 days. Spores were harvested by adding $3 \mathrm{~mL}$ of $0.05 \%$ tween 80 solution. The slanted agar surface was scratched carefully to release the spores from the agar media and spores stock in the form of a suspension was obtained. After diluting the stock spores with a $0.05 \%$ tween 80 solution, a spore concentration of 107 spores $/ \mathrm{mL}$ was obtained. The concentration of spores was determined using a Neubauer haemocytometer (Assistant, Germany).

\subsection{Identification of Chemical Composition}

Gas chromatography (Shimadzu GCMS-QP2010S equipped with an RTX-5MS column) was used to determine the chemical compositions of the oil. Helium was used to transport the gas at a flow rate of $0.5 \mathrm{~mL} / \mathrm{min}$. Operating temperature was programmed to rise at a rate of $4^{\circ} \mathrm{C} / \mathrm{min}$ from 70 to $280^{\circ} \mathrm{C}$. The temperature of the injector was set at $290^{\circ} \mathrm{C}$.

\subsection{Antimicrobial Activity}

The antifungal activity of turmeric leaf essential oil on potato dextrose agar media was investigated using the poisoned food technique (13). The turmeric leaves oil were added in various concentrations ( $0 \% ; 0.25 \% ; 0.50 \% ; 1 \%$; and $2 \%$ ) to the PDA liquid media containing 1\% Tween 80 (Merck, Germany), and then poured into a petri dish. The PDA media was allowed to solidify for a few minutes before it was inoculated with the fungi spores. Each plate was inoculated at three points and incubated at $30^{\circ} \mathrm{C}$. All treatments were compared to PDA with $1 \%$ Tween 80 . The inhibition area percentage of fungal colony growth was calculated using the following equation (14).

$$
\text { Inhibition diameter }(\%)=A=\frac{D c-D o}{D C} \times 100 \%
$$

Note : Dc = Diameter of the control colony

Do $=$ Diameter of the treated colony

All treatments were carried out in 3 replications. Statistical tests with analysis of variance were used to obtain the difference among the means. If a significant difference existed, the analysis was followed with the Duncan's Multiple Range Test (DMRT) at a significance level of $95 \%$.

\section{Result and Discussion}

\subsection{Chemical Compositions of Essential Oil}

The chromatogram obtained from the GC-MS for the essential oils extracted from turmeric leaves is shown in Figure 1 and the chemical compositions of the oil are presented in Table 1. 


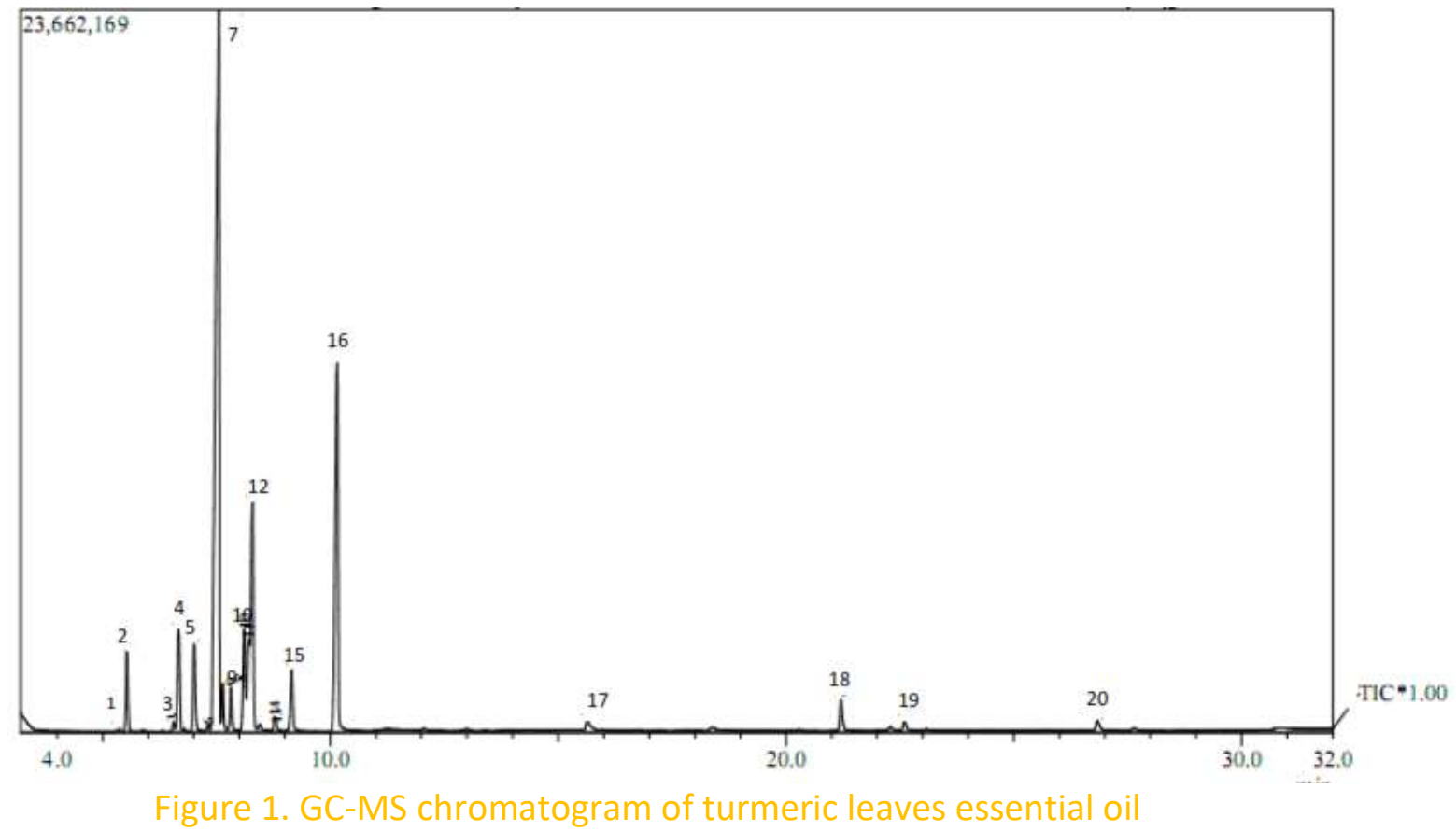

Table 1. Chemicals composition of turmeric leaves essential oil

\begin{tabular}{clc}
\hline No & \multicolumn{1}{c}{ Compound } & Relative content (\%) \\
\hline 1 & $\alpha$-Thujene & 0.13 \\
2 & $\alpha$-Pinene & 2.65 \\
3 & Sabinene & 0.32 \\
4 & 2 - $\beta$ Pinene & 3.64 \\
5 & $\beta$-Myrcene & 3.38 \\
6 & Delta 4-Carene & 0.19 \\
7 & $\alpha$-Phellandrene & 46.70 \\
8 & Delta 3-Carene & 1.48 \\
9 & $\alpha$-Terpinene & 1.50 \\
10 & Benzene & 4.24 \\
11 & 1 -Limonene & 3.59 \\
12 & 1,8 -Cineole & 8.78 \\
13 & cis-Ocimene & 0.24 \\
14 & $1,3,6-$ Octatriene, 3,7-dimethyl & 0.58 \\
15 & $\gamma$-Terpinene & 2.28 \\
16 & $\alpha$-Terpinolene & 17.39 \\
17 & Limonene dioxide & 0.53 \\
18 & $\beta$-Farnesene & 1.37 \\
19 & Farnesene & 0.47 \\
20 & AR-Tumerone & 0.52 \\
\hline
\end{tabular}

The results shown in Table 1 reveals that there were twenty compounds identified in the oil with $\alpha$-phelandren was the largest component (46.70\%) followed by $\alpha$-terpinolene (17.39\%), 1,8-cineole (8.78\%), benzene (4.24\%), and $2-\beta$ pinene $(3.64 \%)$. These findings support the results of previous studies which reported that $\alpha$-phelandrene is the primary component of turmeric leaves essential oil (14-16). These authors reported that as many as 
61 compounds were identified in the essential oil extracted from $C$. longa leaves. McCarron et al (15)reported that $\alpha$-phellandrene (53.4\%), terpinolene $(11.5 \%)$, and 1,8-cineole $(10.5 \%)$ were the most abundant. Dixit (16) reported that the primari components of $C$. longa leaf oil were $\alpha$-phellandrene $(24.5 \%), 1,8$-cineole $(15.9 \%)$, pcymene $(13.2 \%)$, and $\beta$-pinene $(8.9 \%)$. Similar to the finding reported by McCarron et al (15), Oguntimein et al (17) also found that $\alpha$-phellandrene $(47.7 \%)$ and terpinolene $(28.9 \%)$ were the predominant compounds in $C$. longa leaf oil. Therefore, the results of our study are in accordance with the results reported by these researchers.

\subsection{Antifungal Activity}

The effects of turmeric leave oil at various concentration on the mycelia growth of $A$. flavus and $A$. parasiticus during incubation are shown in Figure 2 and Figure 3 respectively and the diameter of the colonies are presented in Figures 4 and 5.

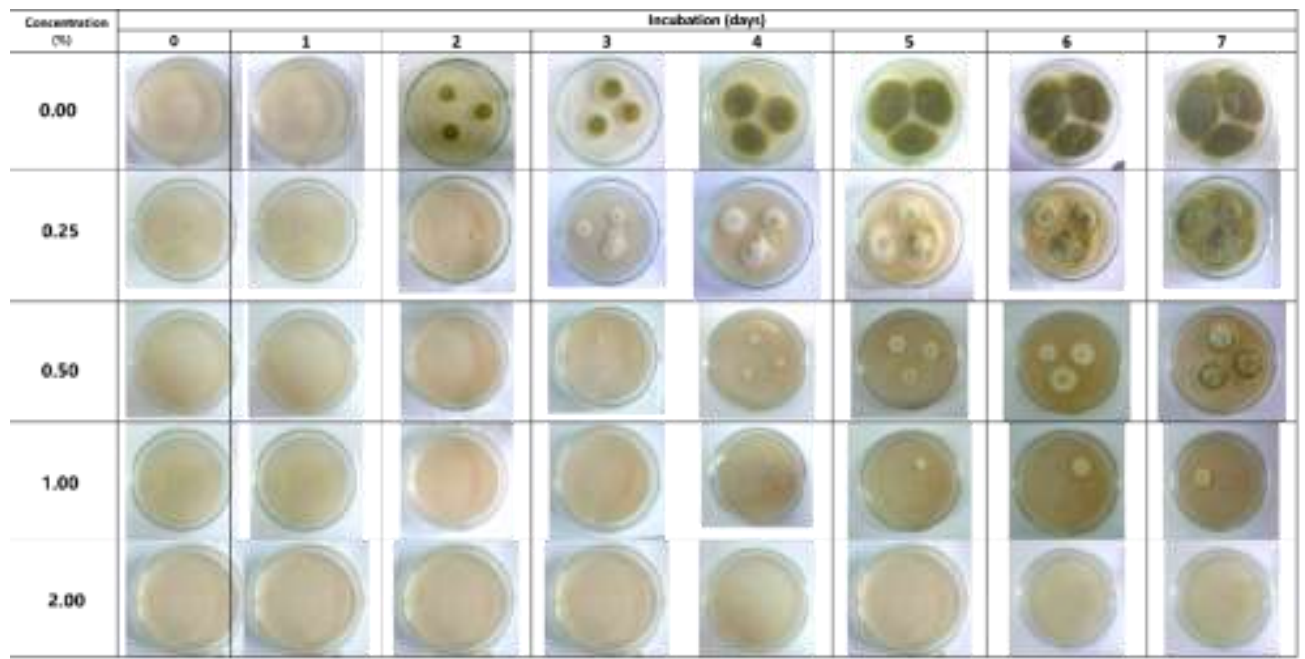

Figure 2. Antifungal activity of essential oil from turmeric leaves against A. flavus

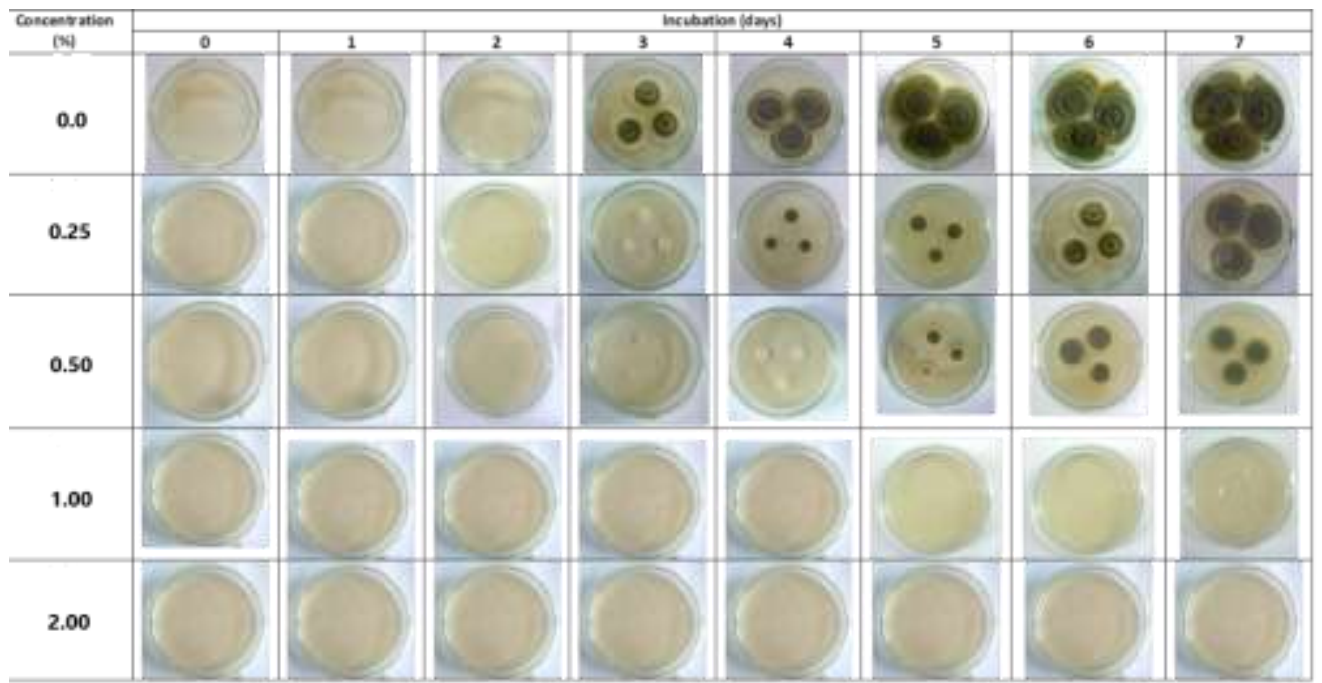

Figure 3. Antifungal activity of essential oil from turmeric leaves against A. parasiticus 


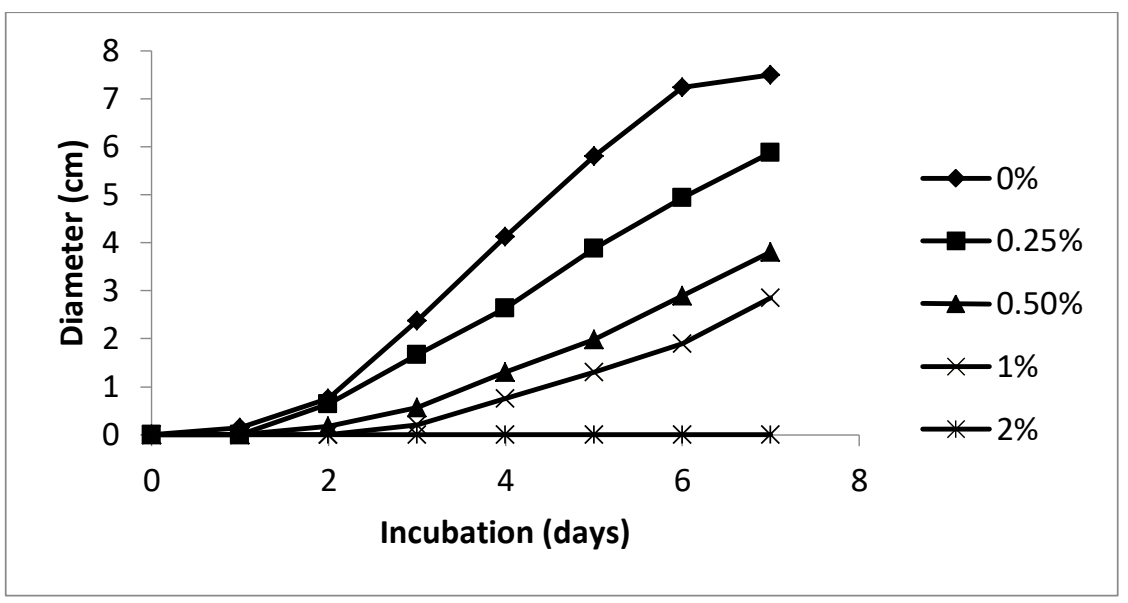

Figure 4. The effect of turmeric leaves oil concentration on mycelia diameter of $A$. flavus during 7 days of incubation

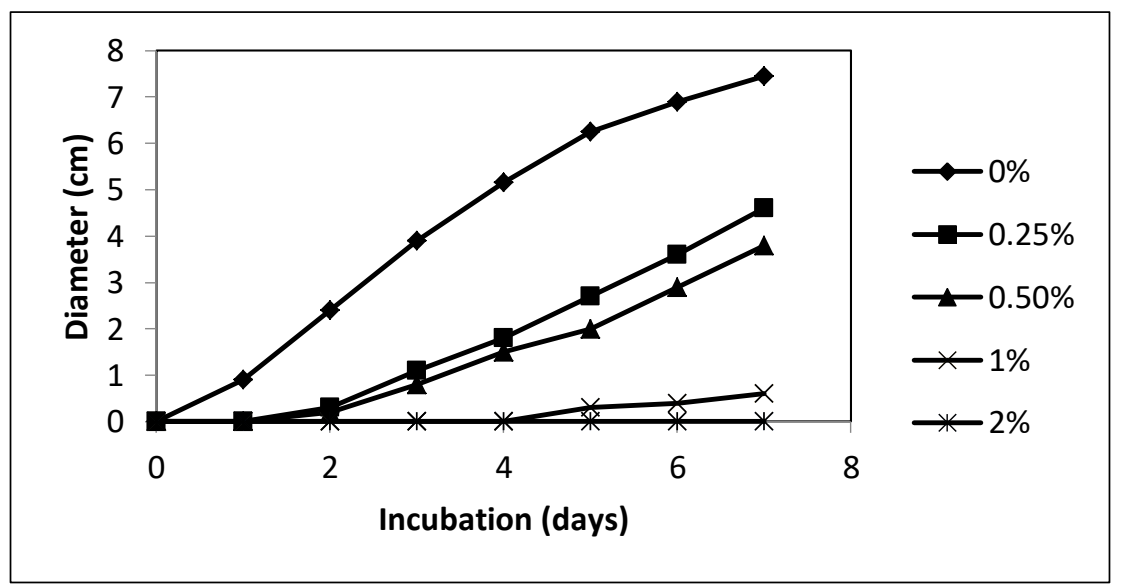

\section{Figure 5. The effect of turmeric leaves oil concentration on mycelia diameter of $A$. parasiticus during 7 days of incubation}

The growth patterns of $A$. flavus and $A$. parasiticus in growth media containing various concentrations of turmeric leaf oil were observed for seven days. The antifungal activity of turmeric leaf oil was demonstrated by its ability to inhibit the growth of $A$. flavus and $A$. parasiticus during seven days of observation. When essential oil was added to the media, mycelia formation was delayed even at concentration of as low as $0.25 \%$. On the first day of incubation, the media without turmeric leaf oil were colonized by $A$. flavus and $A$. parasiticus mycelia. Inhibitions of $A$. flavus and $A$. parasiticus mycelium were demonstrated in media containing $0.25 \%, 0.50 \%, 1.00 \%$, or $2.00 \%$ turmeric leaves oil. On the second day, mycelia began to grow on media treated with $0.25 \%$ and $0.50 \%$ turmeric leaf oil, but no growths were observed on the media with $1.00 \%$ or $2.00 \%$ turmeric leaf oil. At the $1.00 \%$ concentration, $A$. flavus mycelia began to grow on the third day, whereas $A$. parasiticus mycelia began to grow on the fifth day. After seven days of incubation, mycelia of the fungi did not appear in the media containing $2 \%$ turmeric leaf oil. The percentages of the inhibition by turmeric leave oil are shown in Table 2. 


\begin{tabular}{|c|c|c|}
\hline \multirow{2}{*}{$\begin{array}{c}\text { Concentration } \\
\text { of oil (\%) }\end{array}$} & A. flavus & A. parasiticus \\
\hline & Inhibition (\%) & Inhibition (\%) \\
\hline 0 & $0^{a}$ & $0^{a}$ \\
\hline 0.25 & $21.67^{b}$ & $38.26^{b}$ \\
\hline 0.50 & $49.33^{c}$ & $48.99^{c}$ \\
\hline 1.00 & $62.00^{d}$ & $91.95^{d}$ \\
\hline 2.00 & $100.00^{\mathrm{e}}$ & $100.00^{\mathrm{e}}$ \\
\hline
\end{tabular}

A. flavus and $A$. parasiticus growths were inhibited by about $21.67 \%$ and $38.26 \%$, respectively, at the lowest concentration tested $(0.25 \%)$. The higher the concentration of turmeric oil used, the higher the inhibition. A. flavus and $A$. parasiticus growth could be completely inhibited for 7 days at the $2 \%$ concentration. This inhibition was due to $\alpha$-phellandrene, the main components of turmeric leaves oil.

Various phytochemicals such as $\alpha$-Phellandrene, $\beta$-Phellandrene, ocimene, limonene, myrcene, and $\alpha$-caryophyllene have been shown to have in vitro activity against Bacillus sp., Candida albicans, Escherichia coli, Pseudomonas aeruginosa, and S. aureus $(18,19)$. Similarly, Zhang et al. (20) reported that $\alpha$-Phellandrene and Nonanal significantly inhibit the mycelia growth of $P$. cyclopium. These chemicals can disturb the integrity of the fungal cell membrane, leading to the leakage of cell constituent and potassium ions, and causing an intensification of the total lipid content, extracellular $\mathrm{pH}$ and membrane permeability. This inhibitory effect was a result of $\alpha$-phellandrene, one of the primary components of turmeric leaves oil.

The second largest compound in turmeric leaves oil is $\alpha$-Terpinolene. The fraction of Eucalyptus oil with $\alpha$-Terpinolene $88.4 \%$ had a fairly strong activity against $P$. fragi, $E$. coli, $S$. typhimurium, S. aureus, S. cerevisiae at concentrations of $0.1-0.4 \%$ (21).

$\alpha$-Terpinolene is the second most abundant compound in turmeric leaf oil. At concentrations of $0.1-0.4 \%$, the fraction of Eucalyptus oil containing $88.4 \% \alpha$-Terpinolene demonstrated moderate activity against $P$. fragi, E. coli, S. typhimurium, S. aureus, and $S$. cerevisiae (21).

$\alpha$-Pinene is one of the minor components that has the ability to act as an antimicrobial. Essential oil with $\alpha$-pinene $(17.7 \%)$ as the predominant component, exhibits antifungal activity against Fusarium poae at a concentration of $2 \%$ (22). With minimal inhibitory concentrations of 0.02 to $0.15 \%$, coriander oil fraction containing $89.4 \% \alpha$-pinene can inhibit the growth of E. coli, S. typhimurium, L. monocytogenes, S. aureus, and $S$. cerevisiae (21).

\section{Conclusions}

The component of essential oil from turmeric oil were mainly $\alpha$-phelandrene followed by $\alpha$-Terpinolene, 1,8-Cineole, benzene, 2 - $\beta$ Pinene : (17.39\%), (8.78\%), (4.24\%), (3.64\%), respectively.

Turmeric leaves oil indicated to have antifungal activity to A. flavus and A. parasiticus. The use of various concentrations of essential oil of turmeric leaves oil indicate a differences in the level of inhibition on the growth of fungi tested. In addition, the delay in spore 
germination were different in both Aspergillus. In this investigation, the oil showed a better antifungal activity to $A$. parasiticus

The major constituents of turmeric essential oil were $\alpha$-phelandrene, followed by $\alpha$ terpinolene, 1,8-cineole, benzene, and $2-\beta$ pinene $(17.39 \%, 8.78 \%, 4.24 \%$, and $3.64 \%$, respectively). Turmeric leaf oil has been shown to have antifungal activity against Aspergillus flavus and Aspergillus parasiticus. The use of different concentrations of turmeric leaves essential oil indicates a difference in the level of inhibition of the fungi tested. Additionally, the spore germination delay was different in both Aspergillus species. The oil demonstrated great antifungal activity against $A$. parasiticus in this study.

\section{Acknowledgements}

The authors thank The Ministry of Education, Culture, Research, and Technology of the Republic of Indonesia for financial assistance

\section{Author Contributions}

Rini Yanti, Yudi Pranoto, and Muhammad Nur Cahyanto, conceived and designed the experiments; Hermina Nurdiawati and Puji Wulandari performed the experiments; Rini Yanti contributed reagents/material/analysis tools; Rini Yanti wrote the paper.

\section{References}

1. Leong-Škorničková J, Šída O, Marhold K. Back to types! Towards stability of names in Indian Curcuma L.(Zingiberaceae). Taxon. 2010;59(1):269-82.

2. Akarchariya N, Sirilun S, Julsrigival J, Chansakaowa S. Chemical profiling and antimicrobial activity of essential oil from Curcuma aeruginosa Roxb., Curcuma glans K. Larsen \& J. Mood and Curcuma cf. xanthorrhiza Roxb. collected in Thailand. Asian Pac J Trop Biomed. 2017;7(10):881-5.

3. Choi WY, Lee HY. Enhancement of antioxidant activities of Curcuma longa leaves by ultra high pressure extraction. Korean J Med Crop Sci. 2014;22(2):121-6.

4. Priyanka R, Vasundhara M, Ashwini J, Radhika B, Thara BS. Screening Fresh, Dry and Processed Tumeric (Curcuma longa L) Essential Oil Against Pathogenic Bacteria. Int J Pharm Sci. 2015;30(1):49-52.

5. Kim S, Ko S-C, Kim Y-S, Ha S-K, Park H-Y, Park Y, et al. Determination of Curcuma longa L.(Turmeric) leaf extraction conditions using response surface methodology to optimize extraction yield and antioxidant content. J Food Qual. 2019;2019.

6. Bluma R V, Etcheverry MG. Application of essential oils in maize grain: Impact on Aspergillus section Flavi growth parameters and aflatoxin accumulation. Food Microbiol. 2008;25(2):324-34.

7. Davari E, Mohsenzadeh M, Mohammadi G, Rezaeian-Doloei R. Characterization of aflatoxigenic Aspergillus flavus and $A$. parasiticus strain isolates from animal feedstuffs in northeastern Iran. Iran J Vet Res. 2015;16(2):150.

8. Ray B. Fundamental food microbiology. Nutr Food Sci. 2005;35:138-45.

9. Benkerroum N. Chronic and acute toxicities of aflatoxins: Mechanisms of action. Int J Environ Res Public Health. 2020;17(2):423.

10. Kabak B. The fate of mycotoxins during thermal food processing. J Sci Food Agric. 2009;89(4):549-54.

11. Tripathi AK, Prajapati V, Verma N, Bahl JR, Bansal RP, Khanuja SPS, et al. Bioactivities 
of the leaf essential oil of Curcuma longa (var. ch-66) on three species of storedproduct beetles (Coleoptera). J Econ Entomol. 2002;95(1):183-9.

12. Gupta D, Bala P, Sharma YP. Antimicrobial activity of Cymbopogon citratus essential oil against the mycoflora of stored dried fruits of Zanthoxylum armatum. J Environ Biol. 2018;39(6):951-7.

13. Perrucci S, Mancianti F, Cioni PL, Flamini G, Morelli I, Macchioni G. In vitro antifungal activity of essential oils against some isolates of Microsporum canis and Microsporum gypseum. Planta Med. 1994;60(02):184-6.

14. de Billerbeck VG, Roques CG, Bessière J-M, Fonvieille J-L, Dargent R. Effects of Cymbopogon nardus (L.) W. Watson essential oil on the growth and morphogenesis of Aspergillus niger. Can J Microbiol. 2001;47(1):9-17.

15. McCarron M, Mills AJ, Whittaker D, Sunny TP, Verghese J. Comparison of the monoterpenes derived from green leaves and fresh rhizomes of Curcuma longa $L$. from India. Flavour Fragr J. 1995;10(6):355-7.

16. Awasthi PK, Dixit SC. Chemical composition of Curcuma Longa leaves and rhizome oil from the plains of Northern India. J Young Pharm. 2009;1(4):312.

17. Oguntimein BO, Weyerstahl P, Marschall-Weyerstahl H. Essential oil of Curcuma longa L. leaves. Flavour Fragr J. 1990;5(2):89-90.

18. Pérez C, Agnese AM, Cabrera JL. The essential oil of Senecio graveolens (Compositae): Chemical composition and antimicrobial activity tests. J Ethnopharmacol. 1999;66(1):91-6.

19. Costa TR, Fernandes OFL, Santos SC, Oliveira CMA, Lião LM, Ferri PH, et al. Antifungal activity of volatile constituents of Eugenia dysenterica leaf oil. J Ethnopharmacol. 2000;72(1-2):111-7.

20. Zhang J hong, Sun $\mathrm{H}$ long, Chen $\mathrm{S}$ yang, Zeng $\mathrm{LI}$, Wang $\mathrm{T}$ tao. Anti-fungal activity, mechanism studies on $\alpha$-Phellandrene and Nonanal against Penicillium cyclopium. Bot Stud. 2017;58(1):1-9.

21. Delaquis PJ, Stanich K, Girard B, Mazza G. Antimicrobial activity of individual and mixed fractions of dill, cilantro, coriander and eucalyptus essential oils. Int J Food Microbiol. 2002;74(1-2):101-9.

22. Krauze-Baranowska $M$, Mardarowicz $M$, Wiwart $M$, Pobłocka L, Dynowska $M$. Antifungal activity of the essential oils from some species of the genus Pinus. Zeitschrift für Naturforsch C. 2002;57(5-6):478-82. 